\title{
Longitudinal assessment of lung function in extremely prematurely born children
}

Jessica Lo MSc ${ }^{1,}$, Sanja Zivanovic $\mathrm{PhD}^{2,3}$, Alan Lunt BSc ${ }^{2,3}$, Mireia Alcazar-Paris BSc ${ }^{2,3}$, Gwendolyn Andradi MBBS ${ }^{2,3}$, Mark Thomas FRCPCH${ }^{4}$, Neil Marlow FRCPCH${ }^{5}$, Sandy Calvert FRCPCH ${ }^{6}$, Janet Peacock $\mathrm{PhD}^{7,8^{*}}$, Anne Greenough MD $\mathrm{MD}^{2,3,8^{*}}$

* Greenough and Peacock contributed equally to this study

${ }^{1}$ School of Psychiatry, UNSW Medicine, University of New South Wales, Sydney, Australia

${ }^{2}$ MRC and Asthma UK Centre in Allergic Mechanisms of Asthma, King's College London;

${ }^{3}$ Women an Children's Health, School of Life Course Sciences, Faculty of Life Sciences and Medicine, King's College London; ${ }^{4}$ Neonatal Medicine, Chelsea \& Westminster Hospital, London; ${ }^{5}$ Neonatal Medicine, Institute for Women's Health, London; ${ }^{6}$ Child Health, St. George's Hospital, London; ${ }^{7}$ School of Population Health and Environmental Sciences, Faculty of Life Sciences and Medicine, King's College London; ${ }^{8}$ NIHR Biomedical Research Centre at Guy's and St Thomas' NHS Foundation Trust and King's College London.

Corresponding author: A Greenough, NICU, 4th Floor, Golden Jubilee Wing, King's College Hospital, Denmark Hill, London SE5 8RS, UK. Tel: 0203299 3037; Fax: 0203299 8284; email: anne.greenough@kcl.ac.uk

Financial support: The study was funded by National Institute for Health Research (NIHR) Health Technology Assessment Programme number 08/116/10 (a detailed report of the study will be published on their website). The South London Comprehensive Local Research Network supported an administrator (RO) to facilitate recruitment. NM receives part funding from the Department of Health's NIHR Biomedical Research Centre's funding scheme at UCLH/UCL. The research was supported by the National Institute for Health Research 
(NIHR) Biomedical Research Centre based at Guy's and St Thomas' NHS Foundation Trust and King's College London. The views expressed are those of the author(s) and not necessarily those of the NHS, the NIHR or the Department of Health.

Key words: airway function; extreme prematurity; lung volume; small airway function

Running head: Longitudinal assessment of lung function 


\section{ABSTRACT}

Objectives: To assess longitudinally small airway function in children born extremely prematurely and whether there was a correlation between airway function in infancy and at 11 to 14 years.

Working hypotheses: There would be tracking of airways obstruction and small airway function would deteriorate during childhood in those born extremely prematurely. Study design: A longitudinal study.

Patient-subject selection: Thirty-five children with a mean gestational age of 26 weeks had lung function assessed at one year corrected and 11-14 years of age.

Methodology: Lung volumes were measured by helium gas dilution $\left(\mathrm{FRC}_{\mathrm{He}}\right)$ and plethysmography $\left(\mathrm{FRC}_{\text {pleth }}\right)$ and small airway function assessed by calculating the $\mathrm{FRC}_{\mathrm{He}}: \mathrm{FRC}_{\text {pleth }}$ ratio. Airway function was assessed at one year corrected by measurement of airway resistance ( $\mathrm{R}_{\mathrm{aw}}$ ) and at 11-14 years by assessment of $\mathrm{R}_{\mathrm{aw}}$, forced expiratory flow from $75 \%$ of vital capacity $\left(\mathrm{FEF}_{75}\right)$ and forced expiratory volume at one second $\left(\mathrm{FEV}_{1}\right)$.

Results: At the first assessment, the children had a mean (SD) $\mathrm{FRC}_{\mathrm{He}}: \mathrm{FRC}_{\text {pleth }}$ of $0.90(0.13)$ and at the second, $0.83(0.12)(\mathrm{p}=0.035)$. There was a significant $0.54 \%$ decrease $(95 \% \mathrm{CI}$ : $1.02 \%,-0.06 \%)$ in $\mathrm{FRC}_{\mathrm{He}}: \mathrm{FRC}_{\text {pleth }}$ for increased age per year after adjusting for birth weight, gestational age, sex and bronchopulmonary dysplasia $(\mathrm{p}=0.027)$. There were significant correlations between $\mathrm{R}_{\mathrm{aw}}$ at the first assessment and $\mathrm{R}_{\mathrm{aw}}(\mathrm{p}=0.012), \mathrm{FEF}_{75}(\mathrm{p}=0.034)$ and $\mathrm{FEV}_{1}(\mathrm{p}=0.04)$ at $11-14$ years.

Conclusions: These results demonstrate in those born extremely prematurely there is tracking of airway function during childhood. 


\section{INTRODUCTION}

Prematurely born infants frequently suffer troublesome respiratory symptoms and lung function abnormalities in the first two years after birth. Adolescents ${ }^{1-5}$ and adults ${ }^{6-8}$ born very prematurely have been reported to have airways obstruction and impaired exercise tolerance. Small airway function appears to deteriorate during infancy ${ }^{9,10}$. It is not, however, clear whether there are changes in airway obstruction with increased age in older children, as there have been few longitudinal studies and their results conflicting. Certain studies have shown that lung function tracked with increasing age ${ }^{11,12}$, whereas another documented airways obstruction at 7-9 years of age but not at 21 years ${ }^{13}$. In the latter study, however the subjects were relatively mature at birth, their mean gestational age being 31.5 weeks. In contrast, amongst young people born very low birth weight (VLBW) who developed BPD, airway obstruction worsened between 8 and 18 years ${ }^{14}$. In addition, amongst 87 extremely low birth weight (ELBW) survivors lung function significantly deteriorated between eight and twelve years $\left(\mathrm{FEV}_{1}\right.$ from 83 to $77 \%$ expressed as the percent predicted for age, height and sex and $\mathrm{FEV}_{1} / \mathrm{FVC}$ from $84 \%$ to $78 \%$ ); the deterioration was independent of the diagnosis of BPD ${ }^{15}$. Whether there are changes in lung function during childhood in those born extremely prematurely and routinely exposed to antenatal corticosteroids and postnatal surfactant remains to be determined.

The United Kingdom Oscillation Study recruited infants born less than 29 weeks of gestational age ${ }^{16}$. More than $90 \%$ of the infants were exposed to antenatal steroids and postnatal surfactant, hence their results are generalisable to the current, extremely prematurely born population. A subset had measurements at a corrected age of one year of lung volumes by plethysmography $\left(\mathrm{FRC}_{\text {pleth }}\right)$ and helium gas dilution $\left(\mathrm{FRC}_{\mathrm{He}}\right)$ and airways resistance $\left(\mathrm{R}_{\mathrm{aw}}\right)$ was also assessed ${ }^{17}$. The $\mathrm{FRC}_{\mathrm{He}}: \mathrm{FRC}_{\text {pleth }}$ ratio was calculated to assess small 
airway function. The children were reassessed at 11 to 14 years of age with detailed lung function assessments ${ }^{18}$. Our aim was to compare determine if there was a correlation between airway function at a corrected age of one year and at 11-14 years of age and determine if in those children, with paired $\mathrm{FRC}_{\mathrm{He}}$ : $\mathrm{FRC}_{\text {pleth }}$ results, there had been deterioration in small airway function.

\section{PATIENTS AND METHODS}

The children included in this study had been recruited into the United Kingdom Oscillation Study (UKOS) ${ }^{16}$. Infants were randomised to their initial mode of ventilation (high frequency oscillatory ventilation or conventional mechanical ventilation) in the first hour after birth. The initial lung function and follow up study were approved by the South Thames Multicentre Research Ethics Committee and the South West London National Research Ethics Service Committee respectively. All parents gave informed written consent. All assessments were made in the Amanda Smith infant and paediatric respiratory laboratories at King's College Hospital NHS Foundation Trust and performed according to guidelines from the American Thoracic Society and the European Respiratory Society. On arrival, a history was taken and the subject weighed, measured and examined. Appointments were deferred for two weeks if the subject had a respiratory tract infection.

\section{Assessment at one year corrected age}

The full details of the respiratory function assessments are reported elsewhere ${ }^{17}$. In brief, all UKOS babies whose families lived in London were invited to attend King's College Hospital in South London to participate in this study. Infants were sedated with $80-120 \mathrm{mg} / \mathrm{kg}$ of 
chloral hydrate and monitored by pulse oximetry (Datex, Ohmeda 3800, Hatfield, UK). The testing procedure consisted of measurement of FRC by plethysmography $\left(\mathrm{FRC}_{\text {pleth }}\right)$ (Department of Medical Engineering, Hammersmith Hospital, London), FRC by helium dilution $\left(\mathrm{FRC}_{\mathrm{He}}\right)$ (Equilibrated BioSystems, New York, USA) and airways resistance by plethysmography $\left(\mathrm{R}_{\mathrm{aw}}\right)$. The results are expressed as the absolute values and as the percentage predicted for length $\mathrm{FRCpleth}$ and $\mathrm{FRC}_{\mathrm{He}}{ }^{19}$. The $\mathrm{FRC}_{\mathrm{He}}: \mathrm{FRC}_{\text {pleth }}$ ratio was calculated.

\section{Assessment at 11-14 years}

Full details of the respiratory measurements are reported elsewhere ${ }^{18}$. In brief, lung volumes were assessed by measuring functional residual capacity using a helium-dilution technique $\left(\mathrm{FRC}_{\mathrm{He}}\right)$ and by plethysmography $\left(\mathrm{FRC}_{\mathrm{pleth}}\right)$. All measurements were undertaken using a Jaeger Masterscreen PFT system (Carefusion Ltd, Basingstone, UK). Two measurements within $5 \%$ of each other were averaged to calculate the final result ${ }^{20-22}$. The $\mathrm{FRC}_{\mathrm{He}}: \mathrm{FRC}_{\mathrm{pleth}}$ ratio was calculated. Small-airway function was also assessed by measurement of forced expiratory flow at $75 \%$ of the expired vital capacity $\left(\mathrm{FEF}_{75}\right)$ by spirometry. In addition, airway function was assessed by spirometric measurement of forced expiratory volume in one second $\left(\mathrm{FEV}_{1}\right)$, and plethsymographic assessment of $\mathrm{R}_{\mathrm{aw}}$. The absolute lung volumes are presented and all lung-function results are also expressed as the percentage predicted for height ${ }^{23,24}$. Exposure to tobacco was estimated using urinary cotinine. A cotinine level of less than $10 \mathrm{ng}$ per millilitre was defined as undetectable, a level of 10 to $30 \mathrm{ng}$ per millilitre was considered to indicate passive smoking, and a level of more than $30 \mathrm{ng}$ per millilitre was considered to suggest active smoking ${ }^{25}$. 


\section{Assessment of respiratory health}

At age one year corrected, the infants were seen by their local paediatricians who, with the parents, completed a respiratory questionnaire ${ }^{26}$. The parents were asked if their infant wheezed, had received any medicines for chest problems in the previous 12 months or had any hospital admissions for breathing difficulties. When the subjects were 11-14 years of age, their parents completed a questionnaire which included questions regarding respiratory problems prior to their children's assessment.

\section{Analysis}

The change in lung function $\left(\mathrm{FRC}_{\mathrm{He}}\right.$ : $\left.\mathrm{FRC}_{\mathrm{pleth}}\right)$ over time was analysed using mixed models, which took into account the length of time between the two assessments for each child. Sex, gestational age groups (23-25 weeks, 26-28 weeks in keeping with the stratification at randomisation), birth weight and $\mathrm{BPD}$ status $\left(\mathrm{BPD}_{36}\right.$ defined as being oxygen dependent at 36 weeks PMA), were thought to be likely confounders and were adjusted for in the models. If the changes in lung function were significant for each additional year in age, the effect of sex, mode of ventilation and BPD status on the degree of change were examined. This was conducted by adding an interaction term of time and one of the aforementioned variables into the mixed model. If the term had a p-value of $<0.05$, the effect of the variable was considered to be statistically significant. In a sensitivity analysis, oxygen dependency at 28 days was used in the model instead of oxygen dependency at 36 weeks PMA. The relationship between airway function ( $\mathrm{R}_{\mathrm{aw}}$ at a corrected age of one year and airway function $\left(\mathrm{R}_{\mathrm{aw}}, \mathrm{FEF}_{75}\right.$ and $\mathrm{FEV}_{1}$ ) at 11-14 years was examined by the Pearson correlation or the Spearman correlation coefficient as appropriate. Differences in symptom status at each assessment were assessed for statistical significance using McNemar's test. All analyses were performed using Stata v.13.0. 


\section{RESULTS}

Seventy-six infants had pulmonary function assessments at one year corrected age and 44 of those children (58\%) had further lung function assessment at age 11 to 14 years. Thirty-five children had results for $\mathrm{FRC}_{\mathrm{He}}$ and $\mathrm{FRC}_{\text {pleth }}$ at both assessments and form this study's cohort (Figure 1). Missing measurements at the first assessment were due to not being able to obtain technically acceptable recordings or the infant woke before the measurements were complete. Missing data at the follow-up assessment were due to the child's inability to perform the test, results not within $10 \%$ of each other or severe airways obstruction $\left(\mathrm{FEV}_{1} \mathrm{z}\right.$ score less than or equal to -3.5$)$. The study cohort had a lower mean gestational age $(\mathrm{p}=0.04)$; and fewer of the mothers smoked antenatally $(\mathrm{p}=0.04)$ in comparison with those not included, but they were otherwise similar with respect to their baseline characteristics (Table 1). Thirteen percent of infants had wheezy attacks in the first year after birth and nine per cent had received antibiotics (table 1). When cotinine levels were assessed at age 11-14 years, $13 \%$ of the young people were exposed to passive smoking and 9\% likely were active smokers (table 1).

At the first assessment, the children had a mean (SD) FRC $\mathrm{He}_{\mathrm{He}} \mathrm{FRC}_{\mathrm{pleth}}$ of $0.90(0.13)$ and at the second assessment, $0.83(0.12)$ (Table 2) (Figure 2). The lung function changes were then adjusted for several factors: sex, gestational age, birth weight and BPD status (BPD 36$)$. This gave an adjusted mean difference between each child's assessments of - $0.0054,95 \%$ CI 0.0102 to $-0.0006, \mathrm{p}=0.027$. This difference is equivalent to a decrease of $0.54 \%$ (95\% CI: $1.02 \%,-0.06 \%$ ), in $\mathrm{FRC}_{\mathrm{He}}$ : $\mathrm{FRC}_{\text {pleth }}$ for each additional year in age. 
In addition, we tested the model to see if the change in lung function was moderated by any of sex, BPD, mode of ventilation, smoking in pregnancy or passive smoke exposure at age 11-14. None of the interaction tests were statistically significant: sex (interaction $\mathrm{p}=0.37$ ), $\mathrm{BPD}_{36}$ status (interaction $\mathrm{p}=0.69$ ), mode of ventilation (interaction $\mathrm{p}=0.48$ ), smoking in pregnancy (interaction $\mathrm{p}=0.07$ ). Smoking in pregnancy did not appreciably affect the estimated mean change over time ( $0.54 \%$ vs $0.55 \%$ per year) and similarly passive smoke exposure was not significantly related to the change in lung function $(\mathrm{p}=0.62)$ and the interaction test would not converge. Similarly, the interaction test would not converge for active smoking ie was not significant, but only three children were active smokers as defined by their cotinine levels. The sensitivity analysis using BPD defined as oxygen dependency at 28days gave similar results to those above using BPD 36 weeks. (data not shown).

There were significant correlations between $R_{a w}$ at the first assessment and $R_{a w}(r=0.42$, $\mathrm{p}=0.012), \mathrm{FEF}_{75}(\mathrm{r}=-0.37, \mathrm{p}=0.034)$ and $\mathrm{FEV}_{1}(\mathrm{r}=-0.37, \mathrm{p}=0.04)$ at 11 to 14 years.

Questionnaire results of wheeze and use of chest medication were available at both assessments for 31 subjects. The number with wheeze had reduced from eight to three $(p=0.008)$ and the number who used chest medications from sixteen to three $(p<0.001)$. Respiratory hospital admission data were available for 29 subjects and had reduced from 12 requiring admission in the first year after birth to zero at $11-14$ years $(\mathrm{p}<0.001)$. 


\section{DISCUSSION}

We have demonstrated that airway resistance $\left(\mathrm{R}_{\mathrm{aw}}\right)$ at one year corrected correlated with the results at follow-up of $\mathrm{R}_{\mathrm{aw}}, \mathrm{FEF}_{75}$ and $\mathrm{FEV}_{1}$. The results suggest that airway development was impaired. Indeed, at 11-14 years of age the median $\mathrm{FEV}_{1}$ and $\mathrm{FEF}_{75}$ results were at least minus one z score based on data from healthy term born children. Our results are supported by previous results. Extremely preterm infants (gestational ages $<28$ weeks) or extremely low birth weight (ELBW < 1000 grams) were studied at 8 and 18 years. They had substantial airflow impairments at both age and a greater increase in small airway obstruction. Importantly, those who were smokers at 18 years had airway obstruction that increased over time compared with those who did not ${ }^{27}$. Similarly, in ELBW children the obstructive pattern of lung function deteriorated between 8 to 12 years ${ }^{28}$.

A possible explanation for our results is that exposure of the immature lung to the shear stress of mechanical ventilation and/or the higher inspired oxygen concentration compared to in utero may have affected subsequent airway development. Cyclic stretching of isolated lung cells results in production of IL-8 and other inflammatory markers and the magnitude of production was related to the degree of stretch ${ }^{29,30}$. An alternative explanation is that accelerated maturation resulting from intrauterine stress or antenatal corticosteroid administration may have adversely affected airway development. In a non-randomised study, fourteen year olds exposed to antenatal steroids compared to those unexposed had a greater prevalence of larger airway obstruction (35\% versus $21 \%$ ) and were twice as likely to have wheezing in the last 12 months ${ }^{31}$. In our study, all of the subjects had been exposed to antenatal steroids. Such exposure, however, cannot be the only factor, as in one study reporting deterioration of small airway function during infancy, only one of the cohort had antenatal steroid exposure ${ }^{10}$. A further explanation to be considered is the impact of maternal 
antenatal smoking and active adolescent smoking. Antenatal smoke exposure is associated with a reduction in airway function ${ }^{32}$. Parental and active smoking have been demonstrated to act synergistically to affect early lung function deficits in young adulthood ${ }^{33}$. Thirteen percent of mothers in this study smoked antenatally, but neither maternal smoking in pregnancy nor passive smoking adversely influenced the change in lung function with time. Urinary cotinine analysis indicated that $9 \%$ of the young people were likely to have been actively smoking at 11 to 14 years of age, but this amounted to only three children and no significant effect was shown in the change in lung function.

The mean $\mathrm{FRC}_{\mathrm{He}}: \mathrm{FRC}_{\text {pleth }}$ results were statistically significantly lower at 11-14 years compared to one year corrected. This result remained significant after adjusting for birth weight, gestational age, sex and $\mathrm{BPD}_{36}$ status. Those results suggest a deterioration in small airway function with increasing age in the extremely prematurely born young people, who had routinely been exposed to antenatal steroids and postnatal surfactant. Those results however should be interpreted with the caveat that although similar techniques were used at both assessments, different equipment was used to measure $\mathrm{FRC}_{\text {pleth. }}$ It has been shown that FRC measured by certain commercially available equipment was significantly lower than published reference data and lower than data reported for gas dilution techniques ${ }^{34}$. We, however, used a conventional plethysmograph (Department of Medical Engineering, Hammersmith Hospital, London,UK) which has been shown to accurately measures volumes

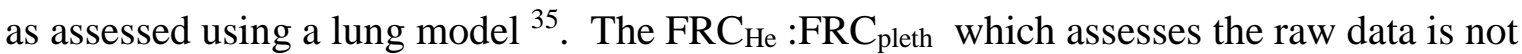
affected by the differences in the reference ranges. The $\mathrm{FRC}_{\mathrm{He}}: \mathrm{FRC}_{\text {pleth }}$ ratio in infancy was similar to that reported in term born infants ${ }^{36}$. We did not report our Raw results as z scores as there is no one reference range which spans the age range of those included in this longitudinal study. Using a reference range which included infants ${ }^{37}$ and one which included 
children aged 2 to 18 years ${ }^{38}$, however,suggests that the Raw results adjusted for weight may not have changed. Hence, we suggest the change in airway function we report may be specific to small airways. The reduction in small airway function was not associated with an increase in symptoms, indeed, there was a statistically significant reduction in the respiratory hospital admission rate. In the first two years, hospitalisation is usually due to lower respiratory tract infections often due to respiratory syncytial virus ${ }^{39}$ and this becomes less of a problem with increasing age. It is possible, however, that children "live within their lung function". In one study, lung function was highest in highly physically active children aged 9 to 10 years ${ }^{40}$. Those results, however, could be interpreted that children with poorer lung function exercise less and, therefore, complain of less symptoms.

There are strengths and some limitations of our study. Similar techniques to assess $\mathrm{FRC}_{\mathrm{He}}$ and $\mathrm{FRC}_{\text {pleth }}$ were used at both assessments, but at one year the infants were assessed supine, whereas at 11 to 14 years the children were assessed while sitting. The latter position would have "benefitted" their lung function, because in the supine position the abdominal contents would have pressed on the diaphragm reducing lung volume. Hence, we might have expected to see a higher $\mathrm{FRC}_{\mathrm{He}}: \mathrm{FRC}_{\text {pleth }}$ ratio, rather than the reverse. We were unable to assess all the children assessed at one year at 11 to 14 years, but those reassessed did not differ significantly from those UKOS children not included, other than this study cohort were born at a shorter mean gestational age and a lower proportion of their mothers had smoked antenatally. This suggests our results are generalisable. We did not adjust the lung function results for ethnicity, but more than $80 \%$ of our subjects were Caucasian. A few of the children had $\mathrm{FRC}_{\mathrm{He}}: \mathrm{FRC}_{\text {pleth }}$ ratios that were greater than one (Figure 2), but as each of their lung volume results fulfilled the ATS guidelines for reproducibility their data were included in the analysis. We did not report our Raw results as percentage predicted for height as our 
Ethics Committee did not allow us to sedate healthy term born infants for the purpose of creating a reference range. In this subset, only $10 \%$ had wheeze at $11-14$ years compared to $15 \%$ in the whole cohort ${ }^{18}$, suggesting our sample was not biased by parents seeking further assessment for a symptomatic child.

In conclusion, we have demonstrated that tracking occurs in lung function between infancy and 11 to 14 years. Our results suggest that there may have been a deterioration in small airway function. Lung function abnormalities in school age children may have important functional consequences. In one study of 9 to 11 year old children, in those born prior to 33 weeks of gestation, airways obstruction was associated with chest CT abnormalities including increased subpleural opacities, bronchial wall thickening and hypo-attenuated lung areas ${ }^{41}$. 


\section{ACKNOWLEDGEMENTS}

Competing interests: AG has held grants from various manufacturers (Abbot Laboratories, MedImmune) and ventilator manufacturers (SLE). AG has received honoraria for giving lectures and advising various manufacturers (Abbot Laboratories, MedImmune) and ventilator manufacturers (SLE). AG is currently receiving a non conditional educational grant from SLE.

Contributor statement: AG and JP designed the study. SZ, MAP, AL, GA and MT collected the data. JL and JP analysed the data. All of the authors critically reviewed the manuscript and approved the final manuscript as submitted.

JLP is a NIHR Senior Investigator. 


\section{REFERENCES}

1 Anand D, Stevenson CJ, West CR, Pharoah PO. Lung function and respiratory health in adolescent of very low birth weight. Arch Dis Child 2003;88:135-138.

2 Kilbride HW, Gelatt MC, Sabath RJ. Pulmonary function and exercise capacity for ELBW survivors in preadolescence: effect of neonatal chronic lung disease. $\mathrm{J}$ Pediatr 2003;143:488-493.

3 Northway WH Jr, Moss RB, Carlisle KB, Parker BR, Popp RL, Pitlick PT, Eichler I, Lamm RL, Brown BW Jr. Late pulmonary sequelae of bronchopulmonary dysplasia. N Engl J Med 1990;323:1793-1799.

4 Fawke J, Lum S, Kirkby J, Hennessy E, Marlow N, Rowell V, Thomas S, Stocks J. Lung function and respiratory symptoms at 11 years in children born extremely preterm. Am J Respir Crit Care Med 2010;18:237-245.

5 Lum S, Kirkby J, Welsh L, Marlow N, Hennessy E, Stocks J. Nature and severity of lung function abnormalities in extremely preterm children at 11 years of age. Eur Respir J 2011;37:1199-1207.

6 Vrijlandt EJ, Gerritsen J, Marike Boezen H, Grevink RG, Duiverman EJ. Lung function and exercise capacity in young adults born prematurely. Am J Respir Crit Care Med 2006;173:890-896.

7 Gough A, Linden M, Spence D, Patterson CC, Halliday HL, McGarvey LP. Impaired lung function and health status in adult survivors of bronchopulmonary dysplasia. Eur Respir J 2014;43:808-816. 
8 Gibson AM, Reddington C, McBride L, Callanan C, Robertson C, Doyle LW. Lung function in adult survivors of very low birth weight, with and without bronchopulmonary dysplasia. Pediatr Pulmonol 2015;50:987-994.

9 Hofhuis W, Huysman MW, van der Wiel EC, Holland WP, Hop WC, Brinkhorst G, de Jongste JC, Merkus PJ. Worsening of V'maxFRC in infants with chronic lung disease in the first year of life: a more favorable outcome after high-frequency oscillation ventilation. Am J Respir Crit Care Med 2002;166:1539-1543.

10 Hoo AF, Dezateux C, Henschen M, Costeloe K, Stocks J. Development of airway function in infancy after preterm delivery. J Pediatr 2002;141:652-658.

11 Filippone M, Sartor M, Zacchello F, Baraldi E. Flow limitation in infants with bronchopulmonary dypslasia and respiratory function at school age. Lancet $2003 ; 361: 753-754$.

12 Vollsaeter M, Roksund OD, Eide GE, Markestad T, Halvorsen T. Lung function after preterm birth: development from mid-childhood to adulthood.Thorax 2013;68:767-776.

13 Narang I, Rosenthal M, Cremonesini D, Silverman M, Bush A. Longitudinal evaluation of airway function 21 years after preterm birth. Am J Respir Crit Care Med 2008;178:74-80.

14 Doyle LW, Faber B, Callanan C, Freezer N, Ford GW, Davis NM. Bronchopulmonary dysplasia in very low birth weight subjects and lung function in late adolescence. Pediatrics 2006;118:108-113. 
15 Hirata K, Nishihara M, Kimura T, Shiraishi J, Hirano S, Kitajima H, Fujimura M. Longitudinal impairment of lung function in school age children with extremely low birth weights. Pediatr Pulmonol 2017;1999:1-8.

16 Johnson AH, Peacock JL, Greenough A, Marlow N, Limb ES, Marston L, Calvert SA; United Kingdom Oscillation Study Group. High-frequency oscillatory ventilation for the prevention of chronic lung disease of prematurity. N Engl J Med 2002;347:633-642.

17 Thomas MR, Rafferty GF, Limb ES, Peacock JL, Calvert SA, Marlow N, Milner AD, Greenough A. Pulmonary function at follow-up of very preterm infants from the United Kingdom oscillation study. Am J Respir Crit Care Med 2004;169:868-872.

18 Zivanovic S, Peacock J, Alcazar-Paris M, Lo JW, Lunt A, Marlow N, Calvert S, Greenough A; United Kingdom Oscillation Study Group. Late outcomes of a randomized trial of high-frequency oscillation in neonates. N Engl J Med 2014;370:1121-1130.

19 Stocks J, Quanjer PH. Reference values for residual volume, functional residual capacity and total lung capacity. ATS Workshop on Lung Volume Measurements. Official Statement of The European Respiratory Society. Eur Respir J 1995;8:492-506.

20 Wanger J, Clausen JL, Coates A, Pedersen OF, Brusasco V, Burgos F, Casaburi R, Crapo R, Enright P, van der Grinten CP, et al. Standardisation of the measurement of lung volumes. Eur Respir J 2005;26:511-522.

21 Coates AL, Peslin R, Rodenstein D, Stocks J. Measurement of lung volumes by plethysmography. Eur Respir J 1997;10:1415-1427. 
22 Clausen JL, Wanger JS. Consensus statement on measurement of lung volumes in humans. ATS/NHLBI consensus document 12 Nov 03 (http://www.thoracic.org/adobe/lungvolume.pdf).

23 Rosenthal M, Bain SH, Cramer D, Helms P, Denison D, Bush A, Warner JO. Lung function in white children aged 4 to 19 years: I -- spirometry. Thorax 1993;48:794-802.

24 Rosenthal M, Cramer D, Bain SH, Denison D, Bush A, Warner JO. Lung function in white children aged 4 to 19 years: II -- single breath analysis and plethysmography. Thorax 1993;48:803-808.

25 Kim S. Overview of cotinine cut-off values for smoking status classification. Int J Environ Res Public Health 2016;13:1236.

26 Greenough A, Yuksel B, Naik S, Cheeseman P, Nicolaides KH. First trimester invasive procedures: effects on symptom status and lung volume in very young children. Pediatr Pulmonol 1997;24:415-422.

27 Doyle LW, Adams AM, Robertson C, Ranganathan S, Davis NM, Lee KJ, Cheong JL, Victorian Infant Collaborative Study Group. Thorax 2017;72:712-719.

28 Hirata K, Nishihara M, Kimura T, Shiraishi J, Hirano S, Kitajima H, Fujimura M. Longitudinal impairment of lung function in school age children with extremely low birth weights. Pediatr Pulmonol 2017;52:779-786.

29 Pugin J, Dunn I, Jolliet P, Tassaux D, Magnenat JL, Nicod LP, Chevrolet JC. Activation of human macrophages by mechanical ventilation in vitro. Am $\mathrm{J}$ Physiol 1998;275:L1040-L1050. 
30 Vlahakis NE, Schroeder MA, Limper AH, Hubmayr RD. Stretch induces cytokine release by alveolar epithelial cells in vitro. Am J Physiol 1999;277:L167-L173.

31 Nixon PA, Washburn LK, O'Shea TM. Antenatal steroid exposure and pulmonary outcomes in adolescents born with very low birth weight. J Perinatol 2013;33:806810.

32 Milner AD, Rao H, Greenough A. The effects of antenatal smoking on lung function and respiratory symptoms in infants and children. Early Hum Dev 2007;83:707711.

33 Guerra S, Stern DA, Zhou M, Sherrill DL, Wright AL, Morgan WJ, Martinez FD. Combined effects of parental and active smoking on early lung function deficits: a prospective study from birth to age 26 years. Thorax 2013;68:1021-1028.

34 Hülskamp G, Hoo AF, Ljungberg H, Lum S, Pillow JJ, Stocks J. Progressive decline in plethysmographic lung volumes in infants: physiology or technology? Am J Respir Crit Care Med 2003;168:1003-1009.

35 Broughton S, Rafferty GF, Milner AD, Greenough A. Progressive decline in FRC in infants: physiology or technology? Am J Respir Crit Care Med 2005;172:1475.

36 McCoy KS, Castile RG, Allen ED, Filbrun DA, Flucke RL, Bary-Yishay E. Functional residual capacity (FRC) measurements by plethysmography and helium dilution in normal infants. Pediatr Pulmonol 1995;19:282-290.

37 Nguyen TT, Hoo AF, Lum S, Wade A, Thia LP, Stocks J. New reference equations to improve interpretation of infant lung function. Pediatr Pulmonol 2013;48:370380. 
38 Koopman M, Zanen P, Kruitwagen CL, van der Ent CK, Arets HG. Reference values for paediatric pulmonary function testing: the Utrecht dataset. Respir Med 2011;105:15-23.

39 Greenough A, Cox S, Alexander J, Lenney W, Turnbull F, Burgess S, Chetcuti PA, Shaw NJ, Woods A, Boorman J, et al. Health care utilisation of infants with chronic lung disease, related to hospitalisation for RSV infection. Arch Dis Child 2001;85:463-468.

40 Berntsen S, Wisloff T, Nafstad P, Nystad W. Lung function increases with increasing level of physical activity in school children. Pediatr Exerc Sci 2008;20:402-410.

41 Simpson SJ, Logie KM, O’Dea CA, Banton GL, Murray C, Wilson AC, Pillow JJ, Hall GL. Altered lung structure and function in mid-childhood survivors of very preterm birth. Thorax 2017;72:702-711. 


\section{FIGURE LEGENDS}

Figure 1: Flow chart for study cohort

Figure 2: $\mathrm{FRC}_{\mathrm{He}}: \mathrm{FRC}_{\text {pleth }}$ results at the first and second assessment

\section{TABLE LEGENDS}

Table 1: Baseline characteristics by inclusion status

Table 2: Lung function results (unadjusted) at the initial and second assessment 